\title{
Study on Civil Aviation Safety Management and Safety Culture
}

\section{Construction}

\author{
Haofeng Wang ${ }^{1, a}$ \\ ${ }^{1}$ China Academy of Civil Aviation Science and Technology, Jia24, Xibahe Beili Chaoyang District \\ Beijing 100028,China \\ awanghf@mail.castc.org.cn
}

Keywords: Safety Management; Safety Culture; Civil Aviation

\begin{abstract}
Safety culture has a long history, which is trace back to the beginning of human activity. The civil aviation safety culture includes several dimensions as advertising culture, reported culture, judicial culture, adaptability culture, and learning culture. We can promote civil aviation safety management level by taking safety culture construction, which could finally make the safety consciousness deeply rooted and ensure aviation safety.
\end{abstract}

\section{Introduction}

As we all know, safety is an important symbol of social civilization and progress, and civil aviation is an important part of the transportation industry, which has high degree of technical optimization and operational risk characteristics. If one flight accident happened, it often brings serious casualties and huge property losses. With the rapid development of the field of civil aviation, it puts forward higher requirements for the safety management level of airlines. And for this purpose, the Civil Aviation Administration of China (CAAC) put forward the "continuous safety" conception in 2008. It focus on promoting the conception system, team system, the legal system, the responsibility system, and highlighting the strengthening of system safety, process safety and so on. The next step, CAAC will improve the overall quality of people, and promote the comprehensive development of people by building a good safety culture.

\section{Concept and Connotation of Safety Culture}

\subsection{The concept of safety culture}

Broadly speaking, safety culture has a long history, since human being appeared, there were safety issues and followed by the protection of human safety and health culture, which we named "safety culture". Safety culture is an invisible and intangible force, and it is the production and operation of enterprises in the long-term production and management activities gradually formed, which is the sum of the characteristics of the concept of safe production , the life and physical state and so on(the development of human safety culture as shown in Table 1). 
Table 1 The development of safety culture ${ }^{[1]}$

\begin{tabular}{|c|c|c|}
\hline Stage & Concept Characteristics & Behavioral Characteristics \\
\hline Ancient & Fatalism Theory & Passive Type \\
\hline Modern & Empiricism Theory & Better late than never \\
\hline Contemporary & System Theory & Man - Machine Loop \\
\hline Developing & Essence Theory & Preventive Type \\
\hline
\end{tabular}

Culture is a collection of values and norms of behavior, safety culture is a blend of safety and culture, it can be divided into spiritual culture, behavioral culture, institutional culture and artifacts culture. Spiritual culture refers to the influence of politics, economy, knowledge, belief and way of thinking on organization and staff. Behavioral culture refers to the organization and employees of the concept, behavior, morality and values. Institutional culture refers to the legal construction of the organization, the level of law enforcement and the legal awareness of employees. Artifacts culture refers to the organization in the production of the safety of the use of technology, tools and staff working environment and identification, etc. In recent years, the importance of safety culture in safety management has been paid great attention. In the ICAO’s State Safety Program (SSP) and safety management system (SMS) ${ }^{[2]}$ documents, all papers put forward specific requirements for the construction of safety culture.

\subsection{Connotation of Civil Aviation Safety Culture}

Civil Aviation is one of the most able to reflect the national comprehensive national strength and the era of science and technology development level of industry. China's civil aviation has formed a competitive aviation safety culture, which includes several dimensions as advertising culture, reported culture, judicial culture, adaptability culture, and learning culture ${ }^{[3]}$.

(1) Advertising culture: Airline supervisors should encourage employees to understand the inherent dangers and risks of their work, and at the same time, employees should have the necessary safety knowledge and emergency response measures.

(2) Reported culture: The foundation of safety culture is report culture, and effective reporting system is the key to identify the weaknesses and vulnerabilities of safety management before the accident occurred. A good reporting system allows employees to be motivated to report on safety issues, and it can also provide valuable feedback to all employees in time.

(3) Judicial culture: Justice means fairness, justice and fairness. In the judicial culture, all employees are responsible for all actions they have undertaken that have an impact on safety, and all decisions must take into account their impact on safety.

(4) Adaptability culture: Under the environment of safety culture, the enterprise should make the traditional system mode update, which suits the situation at the time. So supervisors and employees should have new knowledge and information about technical, institutional and environmental factors, which determine the safety of the operating system.

(5) Learning culture: Encourage people to use new knowledge and skills to improve safety level is the responsibility of supervisors, and anyone who has a better idea or opinion on improving or improving operational safety and efficiency should be welcomed.

\section{Safety culture and safety management}

Safety culture has strengthened the human factors such as people's concept, morality, ethics, attitude, emotion and behavior, that continuously improve the safety awareness of people. So that 
people can change from the passive obedience to the safety management system, into a conscious initiative to act on safety requirements.

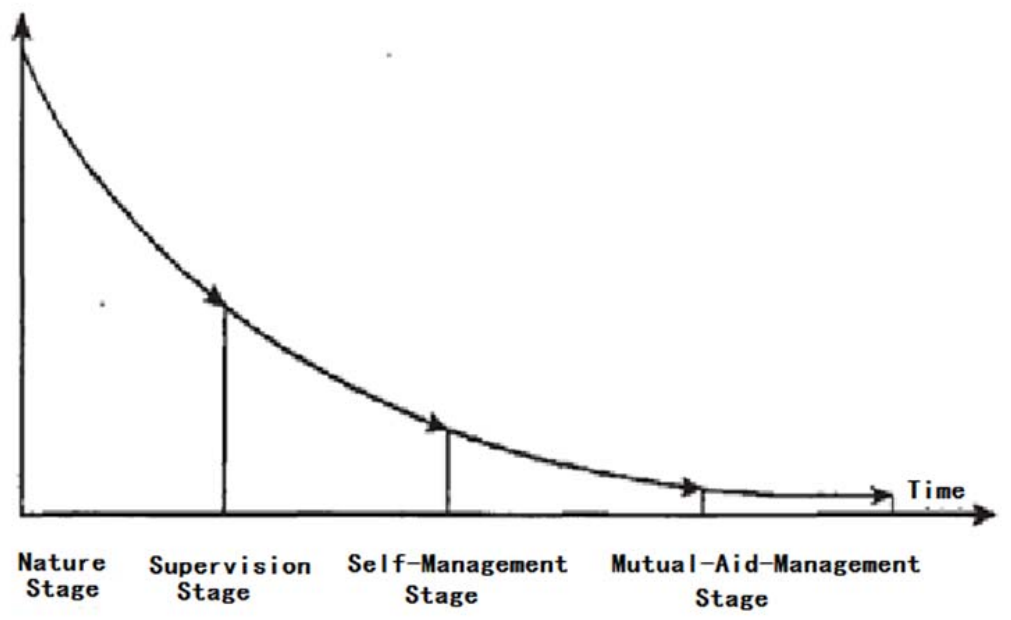

Figure1 Bradley Model Diagram

According to the Bradley model (as shown in Figure 1), the safety management of enterprises must go through 4 stages, including nature stage, strict supervision stage, independent management stage and mutual aid team management stage. The nature stage is characterized by no enterprise safety management regulations, safety management in the state to let things drift; strict supervision stage is characterized by the enterprise has formulated the rules and regulations of the safety management, the leadership and the management layer urge the safety every day, but the staff depends on the supervision to guarantee the safety; independent management stage is characterized by the employees are aware of safety is their own business, they could consciously protect themselves; mutual aid team management stage is characterized by the employees can remind each other and make co-safety. And this should base on the implementation of safety culture.

Safety culture can complement the lack of safety management, just as safety management can complement the lack of safety technology. The civil aviation safety culture should not be separated from "sustainable safety" concept, and it also should not be separated from the construction of the spiritual culture of safety, culture of safe behavior and material culture of safety. And we should carry out the following work as soon as possible.

(1) Carry out institutional culture construction. Institutional culture is not only a fixed form of material culture, but also the main mechanism and carrier of shaping spiritual culture. We should promote and implement safety management standardization, standardization, scientific, which can make aviation safety based on a more stable and reliable system.

(2) Civil aviation has its particular characteristics, such as technical and systemic , that require the industry must have a unified "professional norms", which depends on standardized training. Through the training, employees can form a unified code of conduct, and have clear job specifications and standard job responsibilities.

(3) The construction of safety culture of civil aviation emphasizes to cultivate the advanced safety values based on team spirit, and make everyone take the initiative to avoid unsafe behavior. In the same time, enterprises should encourage the employees to discover safety risks, to propose safety recommendations and make the safety concept into reality.

(4) Airlines and other operating units are both making the main development of the aviation 
industry, and also taking the main responsibility for safety. The safety culture should be infiltrated and integrated into the enterprise safety management by strengthen safety supervision and supervision, and take the responsibility to implement to the departments and individuals. We should focus on forming a good atmosphere of respecting knowledge safety and technology.

\section{Conclusions}

The sustainable development of civil aviation needs to enhance integration of safety culture and safety management. Using scientific management methods and safety training, each employee can strictly enforce the regulations. The dynamic development of civil aviation safety culture is the basis for the continuous improvement of civil aviation safety. A good safety culture atmosphere will play an invaluable role in improving civil aviation safety.

\section{Acknowledgement}

In this paper, the research was sponsored by the civil aviation science and technology project: Research on civil aviation operation safety risk monitoring and prewarning system based on WQAR data (Project No. MHRD20150102).

\section{References}

[1] Luo Yun, The Origin ,Development and Concept of Safety Culture[J], Construction Safety.2002(09):26-27.

[2] ICAO. Annex 19: Safety Management. 2013

[3] Cooper M D. Towards a model of safety culture[J]. Safety Science, 2006(2); 111-136. 